Research Paper

\title{
Effect of rosemary essential oil and modified-atmosphere packaging (MAP) on meat quality and survival of pathogens in poultry fillets
}

\author{
Tolga Kahraman ${ }^{1}$, Ghassan Issa ${ }^{2}$, Enver Baris Bingol ${ }^{1}$, Beren Basaran Kahraman ${ }^{3}$, \\ Emek Dumen ${ }^{1}$ \\ ${ }^{1}$ Department of Food Hygiene and Technology, \\ Faculty of Veterinary Medicine, Istanbul University, Istanbul, Turkey. \\ ${ }^{2}$ Culinary Program, Avrupa Vocational School, Istanbul, Turkey. \\ ${ }^{3}$ Department of Microbiology, Faculty of Veterinary Medicine, Istanbul University, Istanbul, Turkey.
}

Submitted: November 12, 2013; Approved: December 19, 2014.

\begin{abstract}
The effect of rosemary (Rosmarinus officinalis L.) essential oil (REO) and modified-atmosphere packaging (MAP) on the survival of certain pathogens (Salmonella Typhimurium and Listeria monocytogenes) in poultry fillets and on their meat quality during 7 days of refrigerated storage were investigated. Because REO at $0.05 \%$ and $0.1 \%$ had weak antibacterial activity and REO at $0.3 \%$, $0.5 \%$ and $1.0 \%$ imparted unacceptable organoleptic properties, only REO at $0.2 \%$ was used to treat the poultry meat. The results showed that adding $0.2 \%$ REO to poultry fillets did not reduce the size of the population of $S$. Typhimurium and L. monocytogenes. However, REO treatment significantly decreased the $\mathrm{L}^{*}$ (lightness) value and increased the $a^{*}$ (redness) value of stored fillets, and adding REO in combination with MAP reduced the level of lipid oxidation. In conclusion, in a suitable combination, REO can be applied to improve the quality of meat, but further studies should be conducted to determine the appropriate commercial level for different meat products.
\end{abstract}

Key words: rosemary, essential oil, modified-atmosphere packaging, poultry, pathogens.

\section{Introduction}

The production of poultry meat products has increased throughout the world due to its specific sensory attributes and the consumer's belief that white meat is healthier than red meat. Poultry products are highly perishable foods. Therefore, the industry is focused on methods to increase the shelf-life and the overall safety and quality of poultry products (Geornaras et al., 1995; Colak et al., 2011).

The hygienic quality of poultry products depends on the personal hygiene of the handlers, the production method, the qualities of all of the ingredients and the raw meat used (Colak et al., 2011). Many researchers have reported that poultry meat and its products were contaminated by several pathogenic bacteria (Basaran Kahraman and Ak, 2012; Cetinkaya et al., 2008; Mataragas et al., 2008; Urumova et al., 2014). Consumption of products prepared using contaminated poultry meat has been found to be the cause of large outbreaks of salmonellosis and listeriosis (EFSA, 2012). The causative agents of these foodborne pathogens can be present in the gastrointestinal tracts of food-producing animals and can subsequently be transferred to humans through the production, handling and consumption of meat and meat products (Norrung and Buncic, 2008). Salmonella infections were reported to cause approximately 1.4 million cases of foodborne illness and more than 500 deaths per year in the USA (Cetinkaya et al., 2008). In 2010, 99020 cases of human salmonellosis were reported in the EU countries, whereas there were 1,601 cases of human listeriosis in the EU countries that year (EFSA, 2012). To solve these serious food safety problems for consumers, producers are seeking new and improved manufacturing practices to prevent microbiological contamination, survival and growth (Bingol et al., 2013). 
Consumers are increasingly focused on the use of natural products rather than synthetic additives in foods. This trend was reflected in the recently issued EU Directive 2006/52/EC (EU 2006) referring to the necessity of reducing the use of nitrites in processed food. The largest groups of natural compounds are the essential oils and plant extracts. Essential oils are aromatic and volatile oily liquids that are obtained from plant materials, such as leaves, fruits, seeds, and fruits (Gutierrez et al., 2008).

Among the essential oils, rosemary (Rosmarinus officinalis $L$.) oil is widely used for preservation by the food industry. Studies have demonstrated the beneficial effects of rosemary essential oil (REO) as a natural antioxidant that prevented color deterioration and/or lipid oxidation (Aruoma et al., 1992; Balentine et al., 2006; Hussain et al., 2010; $\mathrm{Yu}$ et al., 2002). In addition to its strong antioxidative properties, REO was shown to inhibit the growth of various foodborne pathogens in vitro (Hammer et al., 1999; Smith-Palmer et al., 1998); however, its effectiveness when applied to food has not been extensively investigated.

The practical application of several essential oils in foods is limited due to the strong flavor they impart and their interaction with some food ingredients. The preservative effect of essential oils and extracts may be achieved by using them at lower concentrations in combination with other preservation strategies, such as modified-atmosphere packaging (MAP) (Mastromatteo et al., 2010). MAP has gained considerable acceptance as a modern method for food preservation. MAP is a well-known method for extending the shelf-life of a variety of foods, including poultry and fresh meat (Davies 1995).

The aim of this study was to determine the effect of REO and MAP on the survival of certain pathogens $(S$. Typhimurium and L. monocytogenes) in poultry fillets and on their meat quality.

\section{Materials and Methods}

\section{Extraction of REO}

Leaves collected from rosemary (Rosmarinus officinalis L.) plants in the Aegean region of Turkey were air dried at room temperature $\left(20 \pm 2{ }^{\circ} \mathrm{C}\right)$, and their essential oils were obtained by a 3 -h continuous steam distillation using a Clevenger-type apparatus. The essential oil was collected, dried over anhydrous sodium sulfate and stored at $4{ }^{\circ} \mathrm{C}$ until analysis.

\section{Gas Chromatography}

A $0.4-\mu \mathrm{L}$ aliquot of essential oil was subjected to analysis using capillary gas chromatography. A Thermo Finnigan Trace GC Ultra system (Thermo Electron Corporation, Milan Italy) equipped with an HP-5MS capillary column (30 m x $0.25 \mathrm{~mm})$ with a $0.25-\mu \mathrm{m}$ film thickness was used for this study. The detector and injector were maintained at $275^{\circ} \mathrm{C}$ and $200^{\circ} \mathrm{C}$, respectively. Helium was used as the carrier gas, at a flow rate of $1.0 \mathrm{~mL} / \mathrm{min}$, and the split ratio was set to $100: 1$. The column temperature was programmed as follows: isothermal at $60{ }^{\circ} \mathrm{C}$ for $1 \mathrm{~min}$, ramp to $300{ }^{\circ} \mathrm{C}$ at $3{ }^{\circ} \mathrm{C} / \mathrm{min}$ and isothermal for $1 \mathrm{~min}$. The constituents were identified by comparing their mass spectra with those in the computer library and those of authentic compounds. The identifications were confirmed by comparing their retention times (RT) with those of authentic compounds (1.8-cineole, $\alpha$-pinene, camphor, $2 \alpha$-pinene, camphen and caryophyllene).

\section{Mass spectrometric analysis}

The chemical composition of the REO was determined from gas chromatography-mass spectrometry (GCMS) analysis. Thermo Finnigan Trace DSQ system (Thermo Electron Corporation, Milan Italy), equipped with an HP-5MS capillary column (30 $\mathrm{m} \times 0.25 \mathrm{~mm})$ with a $0.25-\mu \mathrm{m}$ film thickness was used. The chromatographic conditions were identical to those used for the gas chromatographic analysis.

\section{Culture preparation}

Samples of the $S$. Typhimurium (ATCC 14028) and L. monocytogenes (ATCC 7644) strains were obtained from Microbiologics ${ }^{\circledR}$ (Minnesota, USA). Both strains were stored in glycerol $(30 \%)$ at $-80{ }^{\circ} \mathrm{C}$. Samples were streaked on Tryptone Soya Agar (Oxoid CM131, Basingstoke, England) plates and were incubated at $35^{\circ} \mathrm{C}$ overnight. After $24 \mathrm{~h}, S$. Typhimurium and $L$. monocytogenes were grown in aerobically Tryptone Soya Broth (TSB; Oxoid CM129) at $37{ }^{\circ} \mathrm{C}$ until used.

\section{Assays for antibacterial activity}

The antibacterial activity of the REO was assayed as follows: samples of both bacterial cultures $\left(10^{8} \mathrm{cfu} / \mathrm{mL}\right)$ were inoculated into $10 \mathrm{~mL}$ of TSB. Appropriate amounts of the REO solution were added to TSB to achieve final concentrations of $0.05 \%, 0.1 \%, 0.2 \%, 0.3 \%, 0.5 \%$ and $1.0 \%(\mathrm{w} / \mathrm{v})$. Broth samples of all the tested treatments were incubated at $37^{\circ} \mathrm{C}$ for $24 \mathrm{~h}$. To determine the inhibitory effects of REO, samples of the inoculated broth were taken for microbiological analysis at 0, 4, 8, 12 and $24 \mathrm{~h}$ of incubation; all of the analyses were performed in duplicate. The antibacterial activity was determined from the growth of viable $S$. Typhimurium and L. monocytogenes cells on Xylose Lysine Deoxycholate Agar (Oxoid CM469) or Chromogenic Listeria Agar (Oxoid CM1080) for (Solomakos et al., 2008), respectively.

\section{Inoculation of the poultry fillets}

The S. Typhimurium and L. monocytogenes strains were individually prepared by growing samples in $10 \mathrm{~mL}$ of TSB at $30{ }^{\circ} \mathrm{C}$ for $24 \mathrm{~h}$. The bacterial strains were sub-cultured twice using TSB before use. The bacteria were centrifuged $(8000 \mathrm{x} \mathrm{g})$ at $4{ }^{\circ} \mathrm{C}$ for $10 \mathrm{~min}$, washed using 
sterile phosphate-buffered saline (PBS) and serially diluted using PBS to a concentration capable of providing approximately $10^{4} \mathrm{cfu} / \mathrm{g}$ of poultry samples.

Poultry breast meat (totally $21 \mathrm{~kg}$ ) was obtained from a poultry (broiler) processing plant within $12 \mathrm{~h}$ of slaughter. Immediately after delivery, the meat was filleted in small pieces $(20 \mathrm{~g})$. The poultry fillets were divided into three equal groups, and each portion was placed in a polyethylene bag. The samples in the first group were contaminated with only $S$. Typhimurium and those in the second group were contaminated with only L. monocytogenes. The samples in the non-inoculated group were used for physicochemical and sensorial analyses. The samples of poultry fillets were placed in stomacher bags and were inoculated with a single pathogenic strain. The inoculated samples were manually massaged for $10 \mathrm{~min}$ at room temperature $\left(20 \pm 2{ }^{\circ} \mathrm{C}\right)$ to ensure proper distribution of the pathogens. Prior to inoculation, the fillets were examined for contamination by the tested pathogens.

Following homogenization, the inoculated and noninoculated samples (S. Typhimurium, L. monocytogenes and no bacterial inoculum) were treated using four different methods. The treatments were (1) air packaging (2) air packaging + the addition of REO at $0.2 \%$, (3) MAP, (4) MAP + the addition of REO at $0.2 \%$. REO levels of $0.05 \%$ and $0.1 \%$ were not further tested due to their weak antibacterial activities against the selected pathogens. In addition, $0.3 \%, 0.5 \%$ or $1.0 \%$ REO solutions were not applied in the experimental design because of the unacceptable organoleptic properties they imparted to the poultry meat.

Immediately after treatment, all of subgroup samples $(300-350 \mathrm{~g})$ were placed in low- $\mathrm{O}_{2}$-permeable $(8-12$ $\mathrm{cm}^{3} / \mathrm{m}^{2} / 24 \mathrm{~h}$ at STP) polystyrene/ethylvinylalcohol $(\mathrm{EVOH}) /$ polyethylene $(\mathrm{PE})$ trays. For air packaging, the PE trays were over-wrapped using non-barrier polyvinylchloride (PVC) cling film but not sealed to allow exposure to the atmospheric air. For MAP, the PE trays were overwrapped using oxygen-permeable $\left(6000-8000 \mathrm{~cm}^{3} / \mathrm{m}^{2} / 24 \mathrm{~h}\right.$ at STP) polyvinyl-chloride film (Wrap Film Systems Ltd., Shropshire, England) into which a gas mixture of 30\% $\mathrm{CO}_{2} / 70 \% \mathrm{~N}_{2}$ was injected using a Ponapack packaging machine (VTK 40 SC, Ponapack, Istanbul, Turkey). The packages were stored at $4{ }^{\circ} \mathrm{C}$ and were analyzed at $0,1,3,5$ and 7 days to determine the microbiological, physico-chemical (pH, TBA, instrumental color) and sensorial (color, odor, taste and flavor) characteristics, using six packages from each group on each sampling date.

\section{Gas analysis of the package atmospheres}

Gas analyses of the atmosphere within the packages were conducted in duplicate at $1,3,5$ and 7 days of storage. The $\mathrm{CO}_{2}, \mathrm{O}_{2}$ and $\mathrm{N}_{2}$ contents within the packages were determined by injecting $0.5 \mathrm{~mL}$ of gas that had been removed from the headspace using a syringe (B. Braun, Melsungen, Germany) into a PDI gas chromatography system (PBI-
Dansensor A/B, Ronnedevaj 18, Ringsted, Denmark) fitted with a thermal-conductivity detector. The headspace gas levels were calculated by subtracting the $\mathrm{O}_{2} \%$ and $\mathrm{CO}_{2} \%$ after a single direct reading of each package's atmosphere.

\section{Microbiological analysis}

Samples $(25 \mathrm{~g})$ were added to $225 \mathrm{~mL}$ of buffered peptone water (Oxoid CM509) in sterile stomacher bags (Seward, Worthing, England) and were homogenized for 2 min using a stomacher device (Interscience, St. Nom la Breteche, France). Following homogenization, 10-fold serial dilutions were prepared using sterile the Maximum Recovery Diluent (Oxoid CM317), and the diluted samples $(0.1 \mathrm{~mL})$ were streaked onto Xylose Lysine Deoxycholate Agar (Oxoid CM469) and Chromogenic Listeria Agar (Oxoid CM1080) supplemented with Listeria Selective Supplement (Oxoid SR227) and Listeria Differential Supplement (Oxoid SR228) for enumeration of the $S$. Typhimurium and L. monocytogenes, respectively (Harrigan, 1998; Hitchins, 1995). The microbiological analyses were conducted in triplicate.

\section{Physicochemical analysis}

The $\mathrm{pH}$ value of each poultry sample was determined after each exposure period by blending it with $100 \mathrm{~mL}$ of distilled-deionized water $\left(\mathrm{ddH}_{2} \mathrm{O}\right)$ and measuring the value using a pH meter (Hanna HI 1131, Germany) equipped with a combined electrode (HI 9321 Microprocessor $\mathrm{pH}$ meter, Hanna Instruments, Germany) (AOAC 1984).

The color of each sample was measured using a Colorflex HunterLab spectrophotometer (Hunter Associates Laboratory Inc., Reston, VA, USA). Before each measurement, the apparatus was calibrated using a white, a black and a reference standard. Color coordinate values, including the $L^{*}$ (lightness), $a^{*}$ (redness), and $b^{*}$ (yellowness) values were determined based on the average of five readings that were performed at different locations on the surface of the sample. The color was evaluated using diffuse illumination (D65 $2^{\circ}$ observer) with an 8 -mm viewing aperture and a $25-\mathrm{mm}$ port size, with the specular component excluded (Hunt et al., 1991).

The thiobarbituric acid (TBA) content was determined according to the method described by Pearson et al. (1991). The absorbance at $538 \mathrm{~nm}$ was measured using a T80+ UV/VIS spectrometer (PG Instruments Ltd., London, UK). The TBA content was expressed as mg of malondialdehyde (MDA) and was calculated by multiplying the absorbance values by the standard $(\mathrm{K})$ value.

\section{Sensory evaluation of poultry fillets}

The sensorial attributes of the poultry fillets were evaluated by eight experienced panelists ranging from 26 and 45 years of age ( 2 females and 6 males) who were trained according to the ISO protocol (1993). Prior to performing the analysis, the panelists were taught the vocabu- 
laries of the sensory attributes (color intensity, taste and flavor: flavor intensity, spicy taste, salty taste, sweet taste, acidic taste and odor: odor intensity, sour odor, sweet odor, spicy odor) using a standardized procedure (ISO 1998) in two separate sessions of approximately $2 \mathrm{~h}$ for each of the selected attributes, which was followed by an open-discussion session to familiarize the panelists with the attributes and the scales they would use.

The panelists evaluated the perceived intensity of each sensory attribute on 10-cm long unstructured linear scales that were verbally anchored at each end. Simultaneously, the overall acceptability of the poultry meat was assessed using a 5-point descriptive scale in which 1 referred to "dislike extremely" and 5 referred to "like extremely".

The panel members were seated in individual booths in a temperature- and light-controlled room (fluorescent lighting at 2000 lx; Philips 40-W Cool White bulbs) and were given a set of six samples in a completely randomized order. Before the evaluations were performed, the poultry samples were removed from the packages and wrapped in aluminum foil and then were individually cooked in an oven (at $220{ }^{\circ} \mathrm{C}$ ) for $20 \mathrm{~min}$. Each of the samples was served warm in a dish encoded using a three-digit number. Unsalted crackers and water were served to the panelists to freshen their mouths between assessing each sub-sample. The sensory evaluations of the fillets were performed at 1 , 3,5 and 7 days of refrigerated storage at $4{ }^{\circ} \mathrm{C}$.

\section{Statistical analysis}

An analysis of variance was conducted for each variable to investigate the effect of the antibacterial activities of REO during the storage period. The trials were performed in triplicate, and the General Linear Model procedure (PROC GLM) of the SPSS 13.0 package was used to ana- lyze the data (SPSS 2001), with significant differences defined as $\mathrm{p}<0.05$. The microbial counts were expressed as $\log \mathrm{cfu} / \mathrm{g}$ and the mean differences were determined using Duncan's multiple-range tests.

\section{Results and Discussion}

The main volatile components of the REO that was used to treat the poultry fillets were characterized according to the contents of the prominent $(>1 \%)$ components, including those of 1.8 -cineole $(44.80 \%)$, $\alpha$-pinene $(13.17 \%)$, camphor $(10.43 \%), 2 \alpha$-pinene $(8.08 \%)$, camphen $(5.16 \%)$ and caryophyllene (5.07\%). In the present study, 1.8-cineole and $\alpha$-pinene were found to be the major constituents of the REO. Similar results were found in previous studies (Jiang et al., 2011; Pintore et al., 2002). Boutekedjiret et al. (1999) reported that the main component of Tunisian, Turkish and Italian REOs was 1.8-cineole, which accounted for more than $40 \%$ of the total contents. The composition of an REO is affected by the plant variety, the geographical region of cultivation and the extraction method used (Burt 2004).

The antibacterial activities of the REO as determined in TSB units are shown in Figures 1 and 2. In this study, the growth of $S$. Typhimurium and L. monocytogenes were inhibited by the REO at $0.2 \%, 0.3 \%, 0.5 \%$ and $1.0 \%$. Consistent with this result, it has been reported that REO at various concentrations was effective in preventing the growth of food-borne pathogens, such as $S$. Typhimurium (Hammer et al., 1999) and L. monocytogenes (SmithPalmer et al., 1998). In another study, Sagdic and Ozcan (2003) reported that hydrosols of rosemary had no effect on the growth of $S$. Typhimurium. These results showed that the antibacterial activity of REO is affected by the composition of the oil and the strains of bacteria tested. A relation-

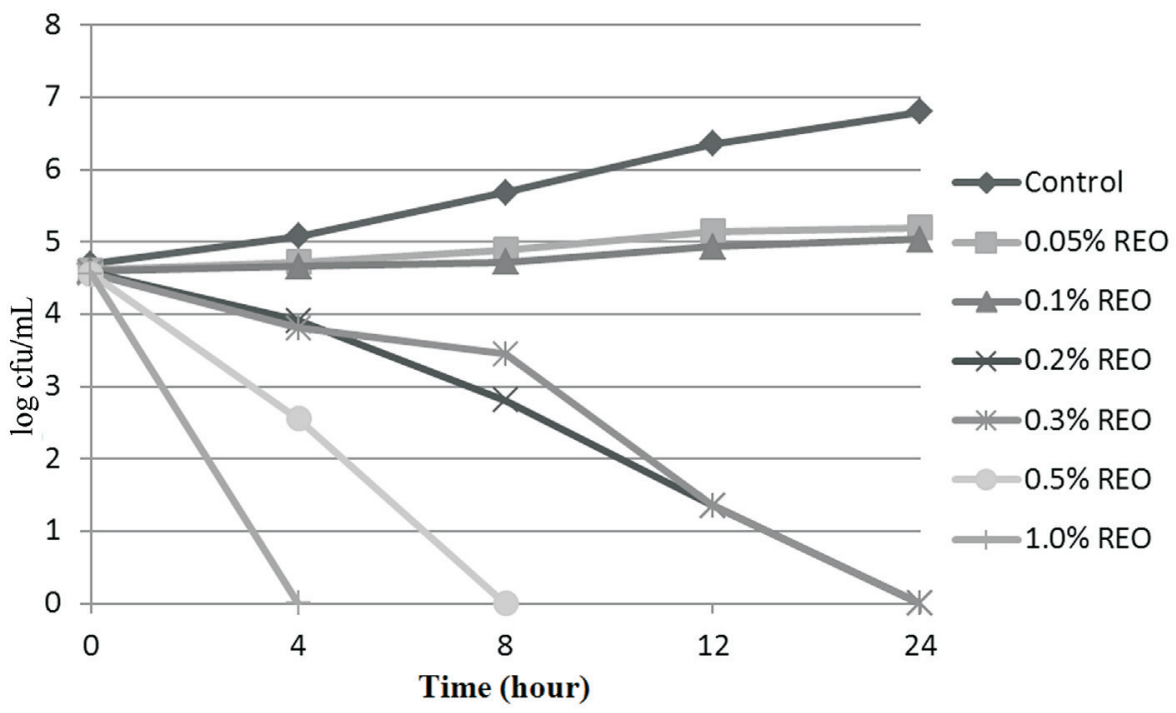

Figure 1 - Effect of the REO on the survival of $S$. Typhimurium in TSB. 


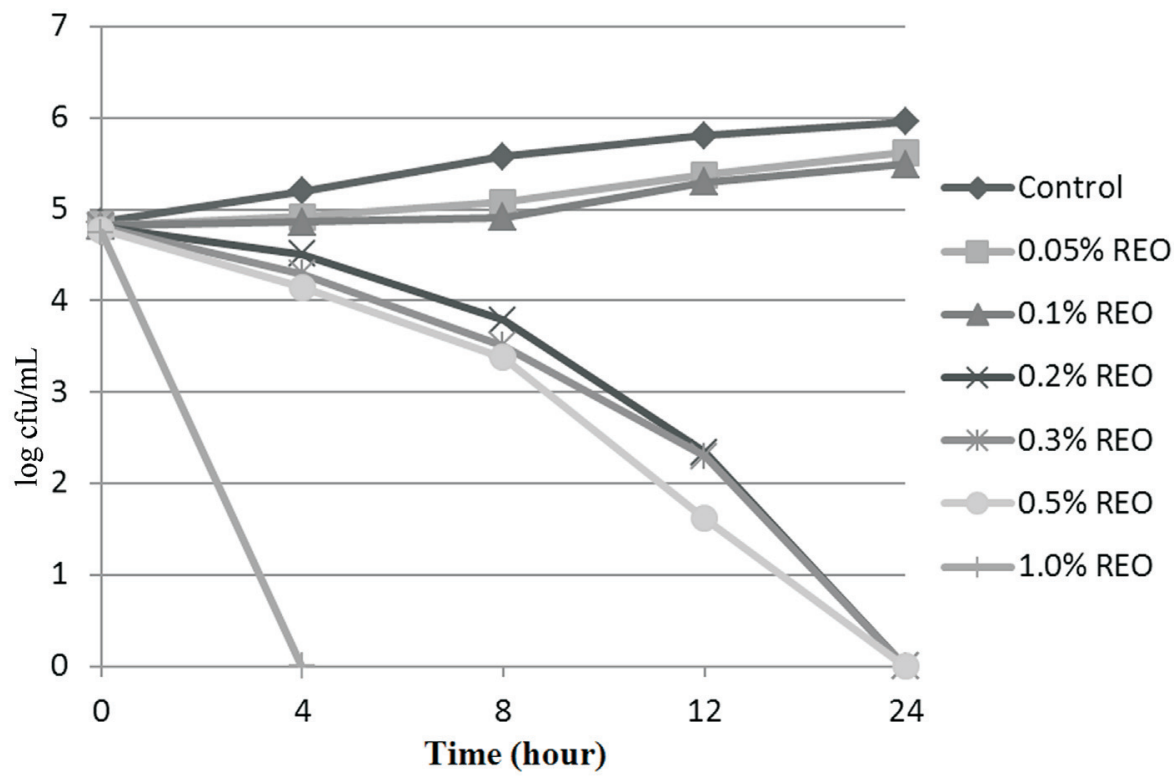

Figure 2 - Effect of the REO on the survival of L. monocytogenes in TSB.

ship between the chemical composition of the tested oil and its antimicrobial activity has been reported (Dimitrijevic et al., 2007). Jiang et al. (2011) found that the bacteriostatic properties of REO appeared to be associated with its 1.8-cineole and $\alpha$-pinene contents.

The mean measured headspace compositions of the packages were as follows: $70.4 \pm 2.8 \% \mathrm{~N}_{2}, 27.1 \pm 0.9 \%$ $\mathrm{CO}_{2}$ and $1.3 \pm 0.7 \% \mathrm{O}_{2}$. The gas composition of each type of packaging were nearly constant during the tested storage period. Similar results have been reported by Bingol and Ergun (2011) and Doherty et al. (1996). These results may be due to the permeability of the packaging material and the respiration rate of the product. The reduction in the $\mathrm{CO}_{2}$ content of the packaged poultry meat was reported to be due to the solubility of $\mathrm{CO}_{2}$ in the aqueous phase of the poultry meats (Seydim et al., 2006).

The sensory properties (odor and taste) of the fillets that had been treated using REO at $0.2 \%$ were assessed by the panelists, who gave scores above $(\mathrm{p}<0.001)$ the rejection limit (a score of 5), whereas the scores given samples that had been treated using the REO at $0.3 \%, 0.5 \%$ and $1.0 \%$ were scored below the rejection limit $(\mathrm{p}<0.001)$. Based on these sensory scores, treatment using $0.2 \%$ REO yielded the highest acceptability scores between 5 and 7 days of storage. Due to the very strong odor and taste of the REO when used at a concentration of $0.3 \%, 0.5 \%$ or $1.0 \%$ during storage, these concentrations were not utilized in the further experiments. Karabagias et al. (2011) evaluated the effect of oregano oil on the odor of lamb meat and found that the sensory data were not generally in agreement with the microbiological data. Ntzimani et al. (2010) found that applying REO $(0.2 \%)$ to cooked chicken produced an acceptable odor and taste. Our findings were similar to these results.

Extracts of volatile compounds obtained from plants are widely used in the food industry due to their ability to inhibit the growth and reduce the number of food-borne pathogens (Kotzekidou et al., 2008). The inhibitory effects of REO on the growth of $S$. Typhimurium and $L$. monocytogenes in poultry fillets are shown in Tables 1 and 2 . In this study, treating poultry meat with $0.2 \%$ REO did

Table 1 - Effect of the REO and MAP on the survival of $S$. Typhimurium in the poultry fillets (log cfu/g).

\begin{tabular}{lcccc}
\hline Storage period (day) & \multicolumn{3}{c}{ Group } \\
\cline { 2 - 5 } & Air & Air $+0.2 \%$ REO & MAP & MAP +0.2\% REO \\
\hline 0 & $4.64 \pm 0.07^{\mathrm{C}}$ & $4.62 \pm 0.05^{\mathrm{C}}$ & $4.66 \pm 0.03^{\mathrm{C}}$ & $4.62 \pm 0.04^{\mathrm{C}}$ \\
1 & $4.78 \pm 0.06^{\mathrm{C}}$ & $4.75 \pm 0.05^{\mathrm{C}}$ & $4.78 \pm 0.05^{\mathrm{C}}$ & $4.75 \pm 0.05^{\mathrm{C}}$ \\
3 & $5.5 \pm 0.07^{\mathrm{B}}$ & $5.53 \pm 0.06^{\mathrm{B}}$ & $5.52 \pm 0.06^{\mathrm{B}}$ & $5.53 \pm 0.06^{\mathrm{B}}$ \\
5 & $5.65 \pm 0.07^{\mathrm{AB}}$ & $5.70 \pm 0.08^{\mathrm{A}}$ & $5.70 \pm 0.05^{\mathrm{A}}$ & $5.66 \pm 0.07^{\mathrm{AB}}$ \\
7 & $5.78 \pm 0.06^{\mathrm{A}}$ & $5.76 \pm 0.03^{\mathrm{A}}$ & $5.76 \pm 0.04^{\mathrm{A}}$ & $5.76 \pm 0.06^{\mathrm{A}}$ \\
\hline
\end{tabular}

A-C: The mean values within a column indicated using different superscripted letters were significantly different $(\mathrm{p}<0.05)$. 
Table 2 - Effect of the REO and MAP on the survival of L. monocytogenes in the poultry fillets (log cfu/g).

\begin{tabular}{lcccc}
\hline Storage period (day) & \multicolumn{3}{c}{ Group } \\
\cline { 2 - 5 } & Air & Air $+0.2 \%$ REO & MAP & MAP $+0.2 \%$ REO \\
\hline 0 & $5.22 \pm 0.05^{\mathrm{C}}$ & $5.20 \pm 0.04^{\mathrm{D}}$ & $5.16 \pm 0.04^{\mathrm{C}}$ & $5.16 \pm 0.04^{\mathrm{D}}$ \\
1 & $5.43 \pm 0.04^{\mathrm{B}}$ & $5.32 \pm 0.03^{\mathrm{C}}$ & $5.33 \pm 0.03^{\mathrm{B}}$ & $5.31 \pm 0.03^{\mathrm{C}}$ \\
3 & $5.47 \pm 0.05^{\mathrm{B}}$ & $5.44 \pm 0.04^{\mathrm{B}}$ & $5.44 \pm 0.04^{\mathrm{B}}$ & $5.44 \pm 0.03^{\mathrm{B}}$ \\
5 & $5.68 \pm 0.03^{\mathrm{A}}$ & $5.64 \pm 0.04^{\mathrm{A}}$ & $5.65 \pm 0.06^{\mathrm{A}}$ & $5.65 \pm 0.03^{\mathrm{A}}$ \\
7 & $5.74 \pm 0.04^{\mathrm{A}}$ & $5.75 \pm 0.04^{\mathrm{A}}$ & $5.71 \pm 0.05^{\mathrm{A}}$ & $5.72 \pm 0.05^{\mathrm{A}}$ \\
\hline
\end{tabular}

The mean values within a column indicated using different superscripted letters were significantly different.

not reduce the populations of $S$. Typhimurium or $L$. monocytogenes $(\mathrm{p}>0.05)$. Our results are agree with those of Fernandez-Lopez et al. (2005), who studied cooked meatballs. Farbood et al. (1976) showed that 1.0\% REO reduced the growth rate of $S$. Typhimurium by $43.2 \%$. Pandit and Shelef (1994) reported that 1.0\% REO inhibited the growth of L. monocytogenes in a pork liver sausage. Moreover, Shelef et al. (1980) demonstrated that Gram-positive bacteria were more sensitive to REO than were Gramnegative bacteria to REO. The differences in susceptibility might be attributed to several factors, including the composition of the REO, the bacterial strain challenged, the $\mathrm{pH}$ of the food product and the storage temperature of the product tested. Moreover, the concentration required to achieve a significant antibacterial effect was considerably higher than the MIC that was determined in vitro (Burt 2004). Notably, the growth of the tested pathogens was not affected by air packaging or MAP. No significant differences were found between the groups $(\mathrm{p}>0.05)$. This result is in agreement with that of a previous study published by Vongsawasdi et al. (2008).

The effect of the combining REO treatment with air packaging or MAP on the $\mathrm{pH}$, color parameter and TBA values of the poultry samples are presented in Table 3. In the present study, the $\mathrm{pH}$ value was not affected $(\mathrm{p}>0.05)$. During storage, the $\mathrm{pH}$ values ranged from 5.92 to 6.07 . Similar results for $\mathrm{pH}$ values were reported by Cajun et al. (2008). Adding REO significantly decreased the $L^{*}$ values $(\mathrm{p}<0.001)$, whereas a significant increase in the $a^{*}$ values $(\mathrm{p}<0.001)$ was observed at 5 and 7 days of storage; the $b^{*}$ values of the samples in the groups remained more similar $(p>0.05)$ throughout the entire storage period. The results indicated that the MAP conditions had no additional effects on the color-parameter values $(\mathrm{p}>0.05)$. Liu et al. (2009) and Sebranek et al. (2005) reported similar findings for chicken meat and pork sausages, respectively. Dogan and Dogan (2004) determined that the polyphenol oxidases, which are enzymes found in many plants, are responsible for a browning reaction. However, McCarthy et al. (2001) and Estevez et al. (2006) found no change in the $a^{*}$ values of frozen pork patties and porcine liver pate, respectively. Balentine et al. (2006) stated that adding REO to ground beef caused an increase in the $b^{*}$ (more yellow) value. The differences among the results may be due to differences in the oxidation pattern of oxymyoglobin in the samples, the storage temperature used, the particular muscle type, the light intensity and the meat species (Georgantelis et al., 2007).

The panelists judged the color attributes of the poultry fillets to be similar to those evaluated instrumentally, in which a slight decrease in the brightness of the samples was observed and a slight increase in the redness was noted in REO-treated fillets. The odor and taste of the air-packaged fillet samples became stronger over time due to the increasing level of lipid oxidation; however, the REO- plus MAPtreated samples remained acceptable throughout storage period. Additionally, the MAP-stored samples were more acceptable than were the samples stored with air in terms of odor (data not shown).

The TBA assay is used to measure of the content of MDA, one of the degradation products of lipid hydroperoxides that is formed through the oxidation of unsaturated fatty acids (Patsias et al., 2006). Fillets to which REO was added had significantly lower TBA values $(p<0.001)$ than did the untreated fillets, and the TBA values increased in all of the groups during the storage period $(\mathrm{p}<0.001)$. The results also showed that adding REO combined with MAP had a strong inhibitory effect on the level of lipid oxidation, whereas the air-packaged fillets had unacceptable TBA values in untreated samples according to the Turkish Standards (TS 2008), with TBA values corresponding to up to $1 \mathrm{mg} \mathrm{MDA} / \mathrm{kg}$ after the $5^{\text {th }}$ day of storage. It is well known that the development of rancidity as a result of lipid oxidation is one of the major factors limiting the storage life of meat products (Bingol et al., 2012). The beneficial effects of REO that were observed in the present study are in agreement with the results of Yu et al. (2002) for turkey and Balentine et al. (2006) for ground beef. Additionally, Aruoma et al. (1992) reported that carnosic acid and carnosol accounted for more than $90 \%$ of the antioxidant properties of a rosemary extract; these compounds are powerful inhibitors of lipid peroxidation. In another study, Chan et al. (1997) determined that controlling its autoxidation using rosemary extract reduced the rate of myoglobin color degradation. In contrast, Rojas and Brewer (2007) reported that the addition of REO did not retard the rate of lipid oxidation 
Table 3 - Effect of the REO and MAP on the pH, color-parameter and TBA values of the poultry fillets.

\begin{tabular}{|c|c|c|c|c|c|c|}
\hline \multirow[t]{2}{*}{ Item } & \multirow[t]{2}{*}{ Group } & \multicolumn{5}{|c|}{ Days of storage } \\
\hline & & 0 & 1 & 3 & 5 & 7 \\
\hline \multirow[t]{4}{*}{$\mathrm{pH}$} & Air & $5.92 \pm 0.04^{\mathrm{D}}$ & $5.93 \pm 0.04^{\mathrm{D}}$ & $5.97 \pm 0.05^{\mathrm{C}}$ & $6.02 \pm 0.09^{\mathrm{B}}$ & $6.06 \pm 0.05^{\mathrm{A}}$ \\
\hline & Air $+0.2 \%$ REO & $5.92 \pm 0.05^{\mathrm{D}}$ & $5.93 \pm 0.06^{\mathrm{D}}$ & $5.97 \pm 0.04^{\mathrm{C}}$ & $6.01 \pm 0.05^{\mathrm{B}}$ & $6.06 \pm 0.05^{\mathrm{A}}$ \\
\hline & MAP & $5.92 \pm 0.03^{\mathrm{D}}$ & $5.93 \pm 0.04^{\mathrm{D}}$ & $5.97 \pm 0.06^{\mathrm{C}}$ & $6.02 \pm 0.07^{\mathrm{B}}$ & $6.07 \pm 0.02^{\mathrm{A}}$ \\
\hline & $\mathrm{MAP}+0.2 \%$ REO & $5.92 \pm 0.04^{\mathrm{E}}$ & $5.93 \pm 0.04^{\mathrm{D}}$ & $5.97 \pm 0.06^{\mathrm{DC}}$ & $6.01 \pm 0.02^{\mathrm{B}}$ & $6.06 \pm 0.05^{\mathrm{A}}$ \\
\hline \multirow[t]{4}{*}{$L^{*}$} & Air & $49.46 \pm 0.07$ & $49.40 \pm 0.10^{\mathrm{a}}$ & $49.36 \pm 0.09^{\mathrm{a}}$ & $49.33 \pm 0.14^{\mathrm{a}}$ & $49.29 \pm 0.04^{\mathrm{a}}$ \\
\hline & Air $+0.2 \%$ REO & $49.46 \pm 0.07^{\mathrm{A}}$ & $48.54 \pm 0.08^{\mathrm{bB}}$ & $47.54 \pm 0.12^{\mathrm{bC}}$ & $47.48 \pm 0.12^{\mathrm{bC}}$ & $46.52 \pm 0.11^{\mathrm{bD}}$ \\
\hline & MAP & $49.46 \pm 0.08$ & $49.53 \pm 0.09^{\mathrm{a}}$ & $49.31 \pm 0.07^{\mathrm{a}}$ & $49.45 \pm 0.13^{\mathrm{a}}$ & $49.46 \pm 0.12^{\mathrm{a}}$ \\
\hline & $\mathrm{MAP}+0.2 \%$ REO & $49.45 \pm 0.08^{\mathrm{A}}$ & $48.51 \pm 0.10^{\mathrm{bB}}$ & $47.51 \pm 0.08^{\mathrm{bC}}$ & $47.46 \pm 0.12^{\mathrm{bC}}$ & $46.56 \pm 0.07^{\mathrm{bD}}$ \\
\hline \multirow[t]{4}{*}{$a^{*}$} & Air & $6.44 \pm 0.12$ & $6.46 \pm 0.10$ & $6.50 \pm 0.11$ & $6.42 \pm 0.12^{\mathrm{b}}$ & $6.48 \pm 0.10^{\mathrm{b}}$ \\
\hline & $\mathrm{Air}+0.2 \%$ REO & $6.39 \pm 0.10^{\mathrm{C}}$ & $6.40 \pm 0.09^{\mathrm{C}}$ & $7.01 \pm 0.22^{\mathrm{B}}$ & $7.53 \pm 0.11^{\mathrm{aA}}$ & $7.58 \pm 0.12^{\mathrm{aA}}$ \\
\hline & MAP & $6.37 \pm 0.08$ & $6.50 \pm 0.10$ & $6.44 \pm 0.09$ & $6.34 \pm 0.07^{b}$ & $6.40 \pm 0.10^{\mathrm{b}}$ \\
\hline & $\mathrm{MAP}+0.2 \% \mathrm{REO}$ & $6.40 \pm 0.12^{\mathrm{C}}$ & $6.42 \pm 0.10^{\mathrm{C}}$ & $6.88 \pm 0.30^{\mathrm{BC}}$ & $7.43 \pm 0.27^{\mathrm{aAB}}$ & $7.60 \pm 0.14^{\mathrm{aA}}$ \\
\hline \multirow[t]{4}{*}{$b^{*}$} & Air & $15.58 \pm 0.09$ & $15.40 \pm 0.05$ & $15.54 \pm 0.04$ & $15.60 \pm 0.06$ & $15.57 \pm 0.08$ \\
\hline & Air $+0.2 \%$ REO & $15.59 \pm 0.07$ & $15.42 \pm 0.10$ & $15.42 \pm 0.11$ & $15.53 \pm 0.12$ & $15.67 \pm 0.08$ \\
\hline & MAP & $15.56 \pm 0.07^{\mathrm{B}}$ & $15.43 \pm 0.06^{\mathrm{AB}}$ & $15.39 \pm 0.08^{\mathrm{AB}}$ & $15.51 \pm 0.12^{\mathrm{AB}}$ & $15.66 \pm 0.07^{\mathrm{A}}$ \\
\hline & $\mathrm{MAP}+0.2 \% \mathrm{REO}$ & $15.62 \pm 0.11$ & $15.37 \pm 0.09$ & $15.41 \pm 0.09$ & $15.42 \pm 0.13$ & $15.67 \pm 0.03$ \\
\hline \multirow[t]{4}{*}{ TBA } & Air & $0.29 \pm 0.04^{\mathrm{E}}$ & $0.51 \pm 0.07^{\mathrm{aD}}$ & $0.67 \pm 0.05^{\mathrm{aC}}$ & $0.98 \pm 0.05^{\mathrm{aB}}$ & $1.26 \pm 0.06^{\mathrm{aA}}$ \\
\hline & Air $+0.2 \%$ REO & $0.29 \pm 0.04^{\mathrm{E}}$ & $0.39 \pm 0.06^{\mathrm{bD}}$ & $0.47 \pm 0.07^{\mathrm{bC}}$ & $0.62 \pm 0.08^{\mathrm{cB}}$ & $0.79 \pm 0.05^{\mathrm{cA}}$ \\
\hline & MAP & $0.29 \pm 0.02^{\mathrm{E}}$ & $0.41 \pm 0.05^{\mathrm{aD}}$ & $0.48 \pm 0.04^{\mathrm{bC}}$ & $0.64 \pm 0.04^{\mathrm{bB}}$ & $0.81 \pm 0.04^{\mathrm{bA}}$ \\
\hline & $\mathrm{MAP}+0.2 \%$ REO & $0.29 \pm 0.02^{\mathrm{E}}$ & $0.33 \pm 0.05^{\mathrm{cD}}$ & $0.38 \pm 0.04^{\mathrm{cC}}$ & $0.57 \pm 0.07^{\mathrm{dB}}$ & $0.75 \pm 0.06^{\mathrm{dA}}$ \\
\hline
\end{tabular}

A, B, C: The mean values within a row indicated using different superscripted letters were significantly different $\mathrm{p}<0.05$ ).

$a, b$, c: The mean values within a column indicated using different superscripted letters were significantly different $(p<0.05)$.

in cooked pork patties during 8 days of storage. The amount of REO added and the composition of its active compounds may be primarily responsible for the different results (Balentine et al., 2006). According to the Turkish Standards (TS 2008), poultry meat with TBA values of greater than $1 \mathrm{mg} \mathrm{MDA} / \mathrm{kg}$ is not suitable for human consumption. In the present study, the TBA values were less than $1 \mathrm{mg}$ $\mathrm{MDA} / \mathrm{kg}$ in the REO plus MAP poultry fillet samples. The $\mathrm{O}_{2}$ concentration is the determining factor for lipid oxidation in chicken meat (Seydim et al., 2006) as it is deferred in air packages.

\section{Conclusion}

The results of this study showed that adding $0.2 \%$ REO to poultry meat did not reduce the growth rate of $S$. Typhimurium or L. monocytogenes at $4{ }^{\circ} \mathrm{C}$ during a 7-day storage period. During storage, the presence of REO significantly decreased the $L^{*}$ values and increased the $a^{*}$ values of the fillets. Adding REO in combination with MAP resulted in lower TBA values in the fillets. In conclusion, in a suitable combination, REO can be applied to improve the quality of meat because it retarded lipid oxidation and prevented the development of rancidity; however, REO did not affect the growth of pathogens when used at the lower levels. Further studies should therefore be conducted to determine the commercial level of REO appropriate for different meat products to allow its application by the food industry.

\section{Acknowledgement}

The authors thank Baran Celik, Samet Topcuoglu and Sukru Sungur from Istanbul University, Faculty of Veterinary Medicine. The authors also thank Turer Tarym for providing the rosemary essential oil. This study was supported by the Research Fund of the University of Istanbul, project number 31911 .

\section{References}

Arouma OI, Halliwell B, Aeschbach R et al. (1992) Antioxidant and prooxidant properties of active rosemary constituents: Carnosol and carnosic acid. Xenobiotica 22:257-268.

Balentine CW, Crandall PG, O'Bryan CA et al. (2006) The preand post-grinding application of rosemary and its effect of lipid oxidation and color during storage of ground beef. Meat Sci 73:413-421. 
Basaran Kahraman B, Ak S (2012) A new pathogen in poultry: Helicobacter pullorum. J Fac Vet Med Istanbul Univ 38:197-205.

Bingol EB, Colak H, Cetin O et al. (2012) Effects of high-oxygen modified atmosphere packaging on the microbiological quality and shelf life of Tekirdag kofte - A Turkish type meatball. J Anim Vet Adv 11:3148-3155.

Bingol EB, Dumen E, Kahraman T et al. (2013) Prevalence of Salmonella spp., Listeria monocytogenes and Escherichia coli $O 157$ in meat and meat products consumed in Istanbul. Med Weter 69:488-491.

Bingol EB, Ergun O (2011) Effects of modified atmosphere packaging (MAP) on the microbiological quality and shelf life of ostrich meat. Meat Sci 88:774-785.

Boutekedjiret C, Belabbes R, Bentahar F et al. (1999) Study of Rosmarinus officinalis L. essential oil yield and composition as a function of the plant life cycle. J Essent Oil Res 11:238240.

Burt S (2004) Essential oils: their antibacterial properties and potential applications in foods-a review. Int J Food Microbiol 94:223-253.

Cadun A, Kisla D, Cakli S (2008) Marination of deep-water pink shrimp with rosemary extract and the determination of its shelf-life Food Chem 109:81-87.

Chan WKM, Faustman C, Decker EA (1997) Oxymyoglobin oxidation as effected by oxidation products of phosphatidylcholine liposomes. J Food Sci 62:709-712.

Cetinkaya F, Cibik R, Soyutemiz EG et al. (2008) Shigella and Salmonella contamination in various foodstuffs in Turkey. Food Control 19:1059-1063.

Colak H, Ugurluay G, Nazli B et al. (2011) The effect of humidity absorbing filters used as packing material on the shelf life of turkey meat. J Fac Vet Med. Istanbul Üniv 37:107-116.

Davies AP (1995) Advances of MAP. In G. W. Gould (ed.): Natural antimicrobial systems and Food Preservation. Blackie, Glasgow, 304-320.

Dimitrijevic SI, Mihajlovski KR, Antonovic DG et al. (2007) A study of the synergistic antilisterial effects of a sub-lethal dose of lactic acid and essential oils from Thymus vulgaris L., Rosmarinus officinalis and Origanum vulgare L. Food Chem 104:774-782.

Dogan S, Dogan M (2004) Determination of kinetic properties of polyphenol oxidase from Thymus (Thymus longicaulis subsp. chaubardii var. chaubardii). Food Chem 88:69-77.

Doherty MA, Sheridan JJ, Allen P et al. (1996) Physical characteristics of lamb primal packaged under vacuum or modified atmospheres. Meat Sci 42:315-324.

EFSA Journal (2012) The European Union Summary Report on trends and sources of zoonoses, zoonotic agents and foodborne outbreaks in 2010. EFSA Journal 10:2597.

Estevez M, Ventanas S, Cava R (2006) Effect of natural and synthetic antioxidants on the protein oxidation and colour and texture changes in refrigerated stored porcine liver pâté. Meat Sci 74:396-403.

European Union (2006) Directive 2006/52/EC of the European Parliament and of the Council of 5 July 2006 amending Directive $95 / 2 / \mathrm{EC}$ on food additives other than colours and sweeteners and Directive 94/35/ EC on sweeteners for use in foodstuffs. Official Journal of the European Union, L204:10-22.
Farbood MI, Macneil JH, Ostovar K (1976) Effect of rosemary spice extractive on growth of microorganisms in meats. $\mathrm{J}$ Milk Food Technol 39:675-679.

Fernandez-Lopez J, Zhi N, Aleson-Carbonell L et al. (2005) Antioxidant and antibacterial activities of natural extracts: Application in beef meatballs. Meat Sci 69:371-380.

Georgantelis D, Blekas G, Katikou P et al. (2007) Effect of rosemary extract, chitosan and a-tocopherol on lipid oxidation and colour stability during frozen storage of beef burgers. Meat Sci 75:256-264.

Geornaras I, Dykes GA, Von Holy A (1995) Biogenic amine formation by chicken-associated spoilage and pathogenic bacteria. Lett Appl Microbiol 21:164 -166.

Gutierrez J, Barry-Ryan C, Bourke P (2008) The antimicrobial efficacy of plant essential oil combinations and interactions with food ingredients. Int J Food Microbiol 124:91-97.

Hammer KA, Carson CF, Riley TV (1999) Antimicrobial activity of essential oils and other plant extracts. J Appl Microbiol $86: 985-990$

Harrigan WF (1998) Laboratory methods in food microbiology. Academic Press Ltd., California.

Hitchins AD (1995) Food and drug administrations, bacteriological analytical manual, $8^{\text {th }}$ Edition. Gaithersburg, USA: AOAC International, 10.01-10.13.

Hunt MC, Acton JC, Benedict RC et al. (1991) Proceedings $44^{\text {th }}$ Annual Reciprocal Meat Conference, AMSA guidelines for meat color evaluation, 3-17.

Hussain AI, Anwar F, Chatha SAS et al. (2010) Rosmarinus officinalis essential oil: antiproliferative, antioxidant and antibacterial activities. Braz J Microbiol 41:1070-1078.

International Standardization Organization (ISO) 8586-1 (1993) Sensory analysis. General guidance for the selection, training and monitoring of assessors. Part 1: Selected assessors. Switzerland.

International Standardization Organization (ISO) 8589 (1998) Sensory analysis-General guidance for design of test rooms. Paris.

Jiang Y, Wu N, Fu Y et al. (2011) Chemical composition and antimicrobial activity of the essential oil of rosemary. Environ Toxicol Pharmacol 32:63-68.

Karabagias I, Badeka A, Kontominas BG (2011) Shelf life extension of lamb meat using thyme or oregano essential oils and modified atmosphere packaging. Meat Sci 88:109-116.

Kotzekidou P, Giannakidis P, Boulamatsis A (2008) Antimicrobial activity of some plant extracts and essential oils against foodborne pathogens in vitro and on the fate of inoculated pathogens in chocolate. Lebensm Wiss Technol 41:119-127.

Liu DC, Tsau RT, Lin YC et al. (2009) Effect of various levels of rosemary or Chinese mahogany on the quality of fresh chicken sausage during refrigerated storage. Food Chem 117:106-113

Machado de Melo AA, Geraldine RM, Silveira MFA et al. (2012) Microbiological quality and other characteristics of refrigerated chicken meat in contact with cellulose acetate-based film incorporated with rosemary essential oil. Braz J Microbiol43:1419-1427.

Mastromatteo M, Conte A, Del Nobile MA (2010) Combined use of modified atmosphere packaging and natural compounds for food preservation. Food Eng Rev 2:28-38. 
Mataragas M, Skandamis PN, Drosinos EH (2008) Risk profiles of pork and poultry meat and risk ratings of various pathogen/product combinations. Intl J Food Microbiol 126:1-12.

McCarthy TL, Kerry JP, Kerry JF et al. (2001) Assessment of the antioxidant potential of natural food and plant extracts in fresh and previously frozen pork patties. Meat Sci 57:177184.

Norrung B, Buncic S (2008) Microbial safety of meat in the Eurepean Union. Meat Sci 78:14-24.

Ntzimani AG, Giatrakou VI, Savvaidis IN (2010) Combined natural antimicrobial treatments (EDTA, lysozyme, rosemary and oregano oil) on semi cooked coated chicken meat stored in vacuum packages at $4{ }^{\circ} \mathrm{C}$ : Microbiological and sensory evaluation. Innov Food Sci Emerg Technol 11:187-196.

Official Methods of Analysis (AOAC) (1984) Washington D.C., USA: Association of Official Analytical Chemists.

Pandit VA, Shelef LA (1994) Sensitivity of Listeria monocytogenes to rosemary (Rosmarinus officinalis L.). Food Microbiol 11:57-63.

Patsias A, Chouliara I, Badeka A et al. (2006) Shelf life of a chilled precooked chicken product stored in air and under modified atmospheres: microbiological, chemical and sensory attributes. Food Microbiol 23:423-429.

Pearson D, Kirk R, Sawyer R (1991) Composition and Analysis of Foods. Longman Scientific \& Technical, Harlow.

Pintore G, Usai M, Bradesi P et al. (2002) Chemical composition and antimicrobial activity of Rosmarinus officinalis L. oils from Sardinia and Corsica. Flavour Frag J 17:15-19.

Rojas MC, Brewer MS (2007) Effect of natural antioxidants on oxidative stability of cooked, refrigerated beef and pork. J Food Sci 72:282-288.

Sagdic O, Ozcan M (2003) Antimicrobial activity of Turkish spice hydrosols. Food Control 14:141-143.

Sebranek JG, Sewalt VJH, Robbins KL et al. (2005) Comparison of a natural rosemary extract and $\mathrm{BHA} / \mathrm{BHT}$ for relative an- tioxidant effectiveness in pork sausage. Meat Sci 69:289296.

Seydim AC, Acton JC, Hall MA et al. (2006) Effects of packaging atmospheres on shelf-life quality of ground ostrich meat. Meat Sci 73:503-510.

Shelef LA, Naglik OA, Bogen DW (1980) Sensitivity of some common foodborne bacteria to the spices sage, rosemary and allspice. J Food Sci 45:1042-1044.

Smith-Palmer A, Stewart J, Fyfe L (1998) Antimicrobial properties of plant essential oils and essences against five important food-borne pathogens. Lett Food Microbiol 26:118122.

Solomakos N, Govaris A, Koidis P et al. (2008) The antimicrobial effect of thyme essential oil, nisin and their combination against Escherichia coli $\mathrm{O} 157: \mathrm{H} 7$ in minced beef during refrigerated storage. Meat Sci 80:159-166.

Statistical Package for the Social Sciences (SPSS) (2001) Release 13.0. IL, Chicago.

Turkish Standard (TS) 2409 (2008). Poultry Carcass. ICS 67.120.20, Ankara.

Urumova V, Stoyanchev T, Lyutskanov M et al. (2014) Antimicrobial sensitivity of Campylobacter jejuni poultry isolates from the Republic of Bulgaria. J Fac Vet Med Istanbul Univ 40:29-34.

Vongsawasdi P, Wongwichan A, Khunajakr N et al. (2008) Shelf-life extensionof fried battered chicken by modified atmosphere packaging. As J Food Ag-Ind 1:197-204.

Yu L, Scanlin L, Wilson J et al. (2002) Rosemary extracts as Inhibitors of lipid oxidation and color change in cooked turkey products during refrigerated storage. J Food Sci 67:582-585.

Associate Editor: Elaine Cristina Pereira De Martinis

All the content of the journal, except where otherwise noted, is licensed under a Creative Commons License CC BY-NC. 